my method $^{\mathbf{1}}$, especially devised for this purpose. The hormone yield is seen in Table 1 .

TARLE 1.

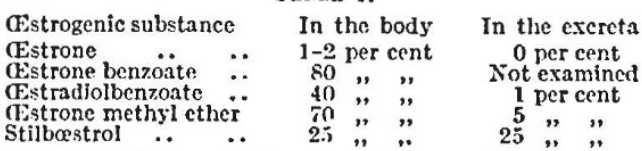

These experiments show that roughly 50 per cent of stilbcestrol can be recovered and that, in this respect, it resembles the hormono esters. It differs from those substances, however, in that half the amount is eliminated in the excreta.

We further investigated tho question whether the slow decomposition in the organism is due to storage at the site of injection, or whether the substances are subject to slow decomposition during their circulation in the body. We injected stilbœstrol and other cestrogenic substances ( 1,000 I.U. in 0.1 c.c. of oil) into the hind-leg of infantile rats, killing the animals after forty-eight hours, and extracted separately the anterior and posterior half (without viscera). I'he result was that stilbostrol was exclusively found in that part which contained tho sito of injection (Table 2).

\begin{tabular}{|c|c|c|}
\hline Estrogenic substance & Anterior laalf & l'osterior hali \\
\hline $\begin{array}{l}\text { diolbenzoate } \\
\text { ne methyl et }\end{array}$ & 0 & 40 per cent \\
\hline Stilbœstrol & $\begin{array}{l}0 \\
0\end{array}$ & $\begin{array}{lll}70 & " \prime\end{array}$ \\
\hline
\end{tabular}

The experiments lead tothe fo llowing conclusions :

(1) In contrast to rendered inactivo in the organism to a small extent, resembling, in this respect, the hormono esters.

(2) Similarly to the hormone esters, stilbœstrol remains deposited at the site of injection for a con. siderablo timo (depot formation) and from there it is slowly absorbed.

(3) Stilbœstrol is distinguished from the hormone esters by the fact that large amounts are eliminated in the excreta, particularly in the urine.

While after absorption the hormone esters are rapidly rendered inactive in the organism, this is not the case with stilbœstrol. In the excreta large amounts of the active substance are found. The fact that the organism is unable to inactivate considerable amounts of stilbœstrol probably helps to explain its eventual toxic activity (compared with estrono) particularly if large doses are used.

Laboratory of the Gynaecological

BerNhard ZoNdek. Felix Suldiax.

Obstetrical Department,

Rothschild-Hadassah University Hospital, Jerusalem. August 19.

17 ondek, R., Lancet, 227, 356 (1938): Scand. Arch. Physiol., 70, 133 (1934); NATCRE, 143, 282 (1939).

2 Dingemanse, E., and Laqueur, E., Amer. J. Obst. ant Gyn., 33. 1000 (1937): Frank Anniversary Tolume.

${ }^{3}$ Dodls, E. C., Golberg, L., Iawson, W., and Robinson, R., TAtcre, 141, 247 (1938)

'7ondek, B., and Brrgmann. E., Biochem. .J., 32, $6 \$ 1$ (1933).

\section{Estimation and Occurrence of Keto-Acids in Green Plants}

Accondivg to the present conception the ketoacids occupy a central position in the synthesis of amino-acids. Attention has been paid especially to the 'fundamental keto-acids', namely, oxaloacetic acid and keto-glutaric acid, since the amino group of aspartic and glutamic acids formed from them is transferred to other keto acids. In green plants, however, keto-acids other than oxaloacetic acidthe presence of which in the growing legumes has recently been demonstrated in this laboratory ${ }^{1}$ have hitherto not been found, evidently due to the absence of suitable methods.

Lately wo have developed the following technique for the determination of keto-acids in plants.

Caustic soda solution and fine quartz sand are added to plant material ${ }^{1}$. The mass is crushed in a mortar and 2-4-dinitrophenylhydrazine solution, strongly acidified with hydrochloric acid, is added to it. The mixture, the $p \mathrm{H}$ of which is less than 1 , is allowed to stand for one hour at room temperature, whereupon anhydrous sodium sulphate is added until the mass is dry. The mass is extracted with ether in the Soxhlet apparatus. The ether solution, which contains the dinitrophenylhydrazones formed, is shaken with sodium carbonate solution. The solution is then made acid with hydrochloric acid and the hydrazones are again precipitated from it by allowing the solution to stand for three days in the ice-box. Tho precipitate is separated, dissolved in alcohol and hydrated according to Tafel ${ }^{2}$ but at near to $0^{\circ} \mathrm{C}$. with sodium amalgam. Amalgam must bo added in small quantities to the reaction solution. Thereby the hydrazones are decomposed so that the keto-acids form the corresponding amino-ncids as a reduction product. Alcohol is distilled away in vacuo and the rest is dissolved in water. The amino-acids formed are determined in the solution. By means of the method in its present form, 80-90 per cent of the keto-acids are found.

In the above manner we have succeeded in finding and determining oxaloacetic acid, keto-glutaric acid and pyruvic acid in growing peas and red clover. For instance, in an experiment with red clover there were found $42 \gamma$ keto-glutaric acid, $18 \gamma$ oxaloacetic acid and $12 \gamma$ pyruvic acid per one gram of fresh material. Investigations aro being continued also with non-legumes. The method is applicable also to the determination of keto-acids in animal material and micro-organisms.

A detailed account of the experiments will be given in the Biochemical Journal.

Biochemical Institute, A. A. Armino.

Helsinki. August 16. Heikn Suomalainfex.

1 Virtanen and Arhimo, Natere, 144, 36 (1939).

${ }^{2}$ Tafel, Ber. deutsch. chem. Ges., 19, 1924 (18S6).

\section{Effect of Ethylene on Mangifera indica}

THE variations in the chemical changes of the respirable substrate accompanying the process of fruit development and ripening of the different varieties of the tropical fruit Mangifera indica were investigated with the view of finding out the nature and the response of the substrate to the different methods of storage. Such investigations would provide helpful information for devising methods of storage of this delicate and easily perishable fruit. Accordingly, investigations as to the changes in the respirable substrate under the different conditions of storage were planned and carried out, first at a lower temperature of $8-12^{\circ} \mathrm{C}$., secondly in ordinary room conditions of $28-32^{\circ} \mathrm{C}$., and thirdly the effect was examined of different concentrations of ethylene gas as a means of artificial ripening.

The presence of ethylene gas is detected in develop. ing Mangifera indica by stunted growth of pea 